\title{
Electrode Properties in Mixed Imidazolium Ionic Liquid Electrolyte
}

\author{
Minato Egashira, * Akinori Kanetomo, Nobuko Yoshimoto, and Masayuki Morita
}

\begin{abstract}
Graduate School of Science \& Engineering, Yamaguchi University (2-16-1 Tokiwadai, Ube, Yamaguchi 755-8611, Japan)
\end{abstract}

\author{
Received November 29, 2009 ; Accepted January 29, 2010
}

\begin{abstract}
The compatibility of the mixed electrolyte of two ionic liquids based on 1,3-substituted imidazolium cations with lithium manganese oxide $\mathrm{LiMn}_{2} \mathrm{O}_{4}$, lithium iron phouphate $\mathrm{LiFePO}_{4}$, graphite, and a hard carbon has been confirmed. For $\mathrm{LiMn}_{2} \mathrm{O}_{4}$ and $\mathrm{LiFePO}_{4}$, the mixed imidazolium ionic liquid electrolyte provides slightly higher plateau in discharge curves, while the initial capacity is slightly lower, when compared with piperidinium ionic liquid. In case of $\mathrm{LiMn}_{2} \mathrm{O}_{4}$, the capacity in the mixed ionic liquid is recovered by subsequent cycling. The thermal stabilities of charged positive electrodes with the mixed ionic liquid, as well as with the piperidinium one, from accelerating rate calorimetry are far over those in conventional carbonate electrolyte. A hard carbon electrode is compatible with the mixed ionic liquid electrolyte.
\end{abstract}

Key Words : Lithium Ion Battery, Ionic Iiquid, Thermal Stability

\section{Introduction}

Focusing on the safety aspect of lithium ion batteries, the searching of advanced materials for electrodes and electrolyte have intensively been investigated. In particular, the replacement of flammable alkyl-carbonate solvents into non-flammable and thermally-stable material has been considered to be effective to suppress the probability of accidental mode caused by the thermal runaway of battery cell. In these years, ionic liquids have been attracted as novel candidates of electrolyte component because of their low volatility, wide electrochemical window, high ionic conductivity, and variety of selection of cation and anion to have desired characteristics. A number of attempts have been made to prepare ionic liquid for this purpose, ${ }^{1-10)}$ and to apply ionic liquids to test cell systems consisting of various positive and negative electrodes.,11-18) Among them, 1-ethyl-3-methyl imidazolium (EMI) bis(fluorosulfonyl)imide (FSI) appears to be an excellent candidate because this material exhibits not only good electrolyte properties such as high ionic conductivity and low viscosity, but good compatibility with graphite negative electrode as well as various positive electrodes. ${ }^{8)}$ However, some researchers have worried about the small impact of this ionic liquid for the improvement of thermal stability of battery cell. ${ }^{19}$ ) Recently the expected application field of lithium ion batteries has been wider and wider, and thus it may be better to propose more and more ionic liquid candidates having various characteristics.

The authors have investigated the properties of a series of ionic liquids having 1-cyanomethyl-3-methyl imidazolium (CmMI) cation and bis(trifluoromethanesulfonyl)imide (TFSI) anion on the focus of utilizing in lithium batteries. ${ }^{20-22)}$ By mixing CmMITFSI with LiTFSI and EMITFSI at appropriate ratio, the mixed ionic liquid electrolyte with the moderate conductivity and the filmforming property on lithium metal electrode that enable the reversible dissolution-plating of lithium. ${ }^{20)}$ In the present study, the compatibility of the mixed ionic liquid electrolyte based on CmMITFSI and EMITFSI with some positive electrodes and carbonaceous negative electrodes have been confirmed. For the positive electrodes combined with this electrolyte, spinel-type lithium manganese oxide $\mathrm{LiMn}_{2} \mathrm{O}_{4}$ and olivine-type lithium iron phosphate $\mathrm{LiFePO}_{4}$ were selected on the focus of utilizing large-scale battery cells. The thermal behavior of the positive electrodes with coexistence of this electrolyte has also been estimated here.

\section{Experimental}

An active material of positive electrode, $\mathrm{LiMn}_{2} \mathrm{O}_{4}$ (Toda Kogyo Co., Japan) or $\mathrm{LiFePO}_{4}$ (provided by Hohsen Co., Japan) was mixed with acetylene black and poly(vinylidene difluoride) (PVdF; Kureha Chemical Co., Japan) binder as the gravimetric ratio of active material: $\mathrm{AB}: \mathrm{PVdF}$ was $8: 1: 1$ in 2-methylpirrolidinone (NMP) solvent. The resulting slurry was spread onto an aluminum foil, dried under vacuum, and then composite electrode sheet was obtained. An artificial graphite (TIMCAL, KS-6) or a hard carbon (Kureha Chemical Co., Japan, Carbotron P) were used as negative electrodes. An active material and PVdF $(6 \mathrm{wt} \%)$ were mixed in NMP solvent and electrode sheet was prepared on a cupper foil. To assemble in a coin cell, these electrode sheets were cut into a disk with $15 \mathrm{~mm}$ in diameter. The loading amount of active material in a coin cell was $c a$. $1.7 \mathrm{mg}$ both for positive and negative electrodes.

EMITFSI and CmMITFSI were kindly provided by Nippon Gosei Kagaku Co., Japan. N-methyl-N-propylpiperidinium bis(trifluoromethanesulfone)imide (PP13TFSI; Kanto Chemical Co., Japan) was used for comparison. The ionic liquid electrolytes with the molar ratio of EMITFSI : CmMITFSI : LiTFSI and PP13TFSI: LiTFSI became $6: 2: 2$ and $8: 2$, respectively was pre- 
pared. The former and the latter electrolytes are denoted later as EMI : CmMI and PP13, respectively. Some properties, such as the room temperature conductivity and viscosity, of EMI : CmMI electrolyte were already presented previously. ${ }^{22}$ :

A 2032 stainless-steel coin cell was assembled with test electrode above, lithium metal counter electrode, electrolyte and separator (Celgard 2500 for positive electrodes and Whatmann glass filter for negative electrodes). The LiTFSI/ionic liquid electrolytes described above, and the electrolyte solution of $0.8 \mathrm{~mol} \mathrm{dm}^{-3} \mathrm{LiPF}_{6}$ in the mixed solvent of ethylene carbonate (EC) and diethyl carbonate (DEC) with the volumetric ratio of $2: 1$ (later denoted as EC : DEC) were used here. Charge-discharge tests of the two-electrode cells under constantcurrent conditions were conducted with a cycle test apparatus (BTS2004, Nagano Co., Japan). The cut-off voltages were from $3.5 \mathrm{~V}$ to $4.6 \mathrm{~V}$ for $\mathrm{LiMn}_{2} \mathrm{O}_{4}$, from $2.5 \mathrm{~V}$ to $3.8 \mathrm{~V}$ for $\mathrm{LiFePO}_{4}$, and from $2.0 \mathrm{~V}$ to $-0.01 \mathrm{~V}$ for carbon electrodes. The applied current density was $0.02 \mathrm{~mA} \mathrm{~cm}^{-2}$ $(c a .1 / 10$ C). These measurements were conducted at room temperature.

The thermal stability of positive electrodes at charged state with coexistence of electrolyte was estimated by accelerated rate calorimetry (ARC), using a special calorimeter (RADEX, Systag. Co., Switzerland). A positive electrode sheet after charged at cut-off voltage as acquired from the cell was placed in a glass vessel with $0.3 \mathrm{~cm}^{-3}$ of electrolyte. The vessel was sealed in a steinless-steel autoclave, and put into the chamber. The temperature of the vessel was initially set at $80^{\circ} \mathrm{C}$, increased stepwise by $10 \mathrm{~K}$ and hold at 30 minutes. Once the selfheating started, the vessel was hold in adiabatic atmosphere and the temperature increase was monitored.

\section{Results and Discussion}

Figure 1 shows the typical (at initial state) charge-discharge profiles of (a) $\mathrm{LiMn}_{2} \mathrm{O}_{4}$ and (b) $\mathrm{LiFePO}_{4}$ positive electrodes in the EC: DEC organic solvent electrolyte and the ionic liquid electrolytes. It is clear that the intercalation process of both $\mathrm{LiMn}_{2} \mathrm{O}_{4}$ and $\mathrm{LiFePO}_{4}$ occurs in the both ionic liquid electrolytes. The discharge capacities and the charge-discharge efficiencies for $\mathrm{LiMn}_{2} \mathrm{O}_{4}$ in EC : DEC, EMI : CmMI, and PP13 electrolytes are 105, $85,87 \mathrm{mAh} \mathrm{g}^{-1}$ and 94, 94, 95\%, respectively. For $\mathrm{LiFePO}_{4}$, The discharge capacities and the charge-discharge efficiencies in EC : DEC, EMI : CmMI, and PP13 electrolytes are 146, 113, $134 \mathrm{mAh} \mathrm{g}^{-1}$ and $98,100,90 \%$, respectively. Both positive electrodes exhibit nominal capacity values in the EC : DEC organic solvent electrolyte. The discharge capacities of these positive electrodes in the ionic liquid electrolytes are lower than those in the EC : DEC. However, the precise behavior is different by the electrolyte EMI : CmMI and PP13. In the PP13, both electrodes exhibit typical profiles with large overpotential. In the EMI : CmMI, the discharge curve of both electrodes exhibit plateau at higher voltage than in the PP13, while the capacity of $\mathrm{LiMn}_{2} \mathrm{O}_{4}$ is similar and that of $\mathrm{LiFePO}_{4}$ is lower. Such low capacities in the EMI : CmMI electrolyte may be due to the low
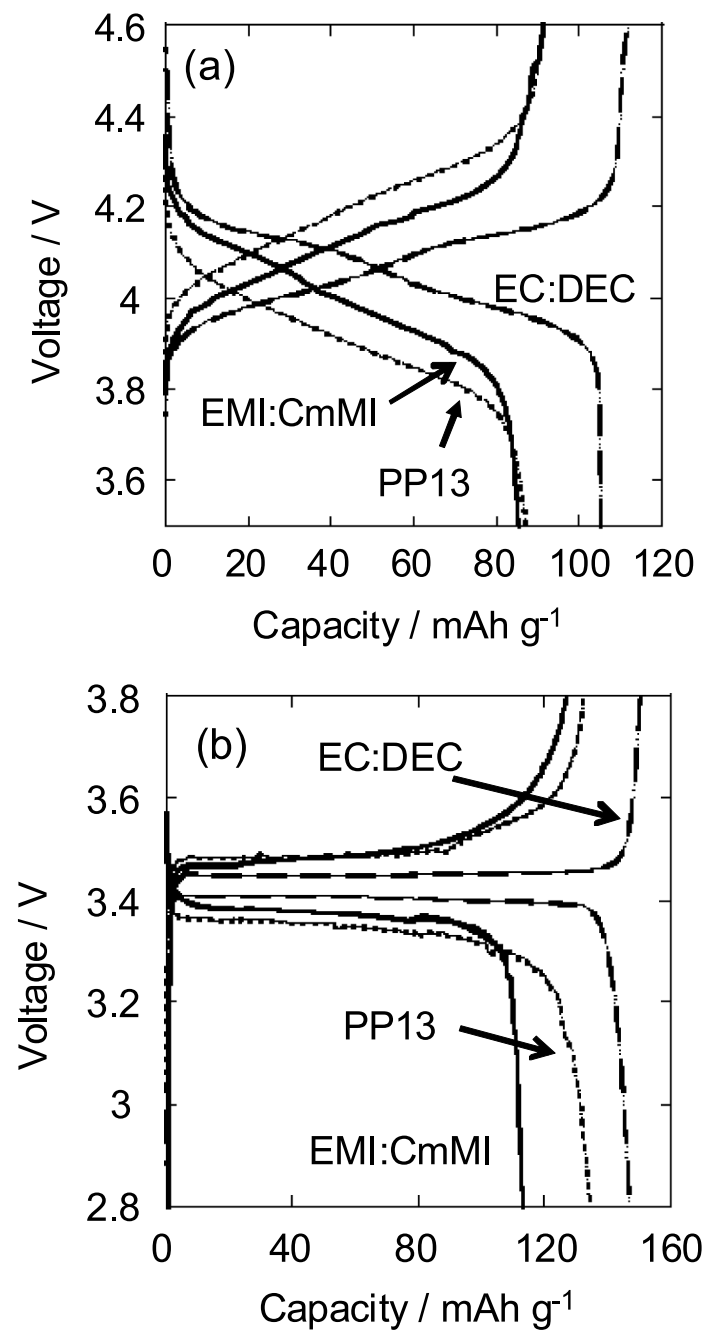

Fig. 1 Charge-discharge profiles of the Li/positive electrode cells in various electrolytes. Electrode: (a) $\mathrm{LiMn}_{2} \mathrm{O}_{4}$ (b) $\mathrm{LiFePO}_{4}$. Current density: $0.02 \mathrm{~mA} \mathrm{~cm}{ }^{-2}$, Cut-off voltage: (a) $3.5-4.6 \mathrm{~V}$, (b) $2.5-3.8 \mathrm{~V}$.

wettability of CmMITFSI having polar moiety toward carbon conductive agent.

The discharge capacities and the charge-discharge efficiencies in the EMI : CmMI electrolyte are plotted over cycles in Fig. 2. In the EMI : CmMI both $\mathrm{LiMn}_{2} \mathrm{O}_{4}$ and $\mathrm{LiFePO}_{4}$ exhibit good cycle performances with capacity retention during initial 30 cycles. In particular, the discharge capacity of $\mathrm{LiMn}_{2} \mathrm{O}_{4}$ increase steeply up to 100 $\mathrm{mAh} \mathrm{g}^{-1}$ during initial several cycles, comprising that the penetration of electrolyte into porous composite electrode is improved. In the case of $\mathrm{LiFePO}_{4}$ such significant increase of capacity would not be observable, probably due to the coating of the surface by carbon. The charge-discharge efficiencies of both electrodes are close to $100 \%$, indicating no significant side reaction occurs.

The behavior of temperature of (a) electrolytes themselves, (b) $\mathrm{LiMn}_{2} \mathrm{O}_{4}$ and (c) $\mathrm{LiFePO}_{4}$ with coexistence of various electrolytes is summarized in Fig. 3 . The switching temperature from the stepwise increase to the rather series increase of temperature can be assumed as the initial temperature of the self-heating for a certain sample. The self-heating temperatures for EC : DEC, EMI : 

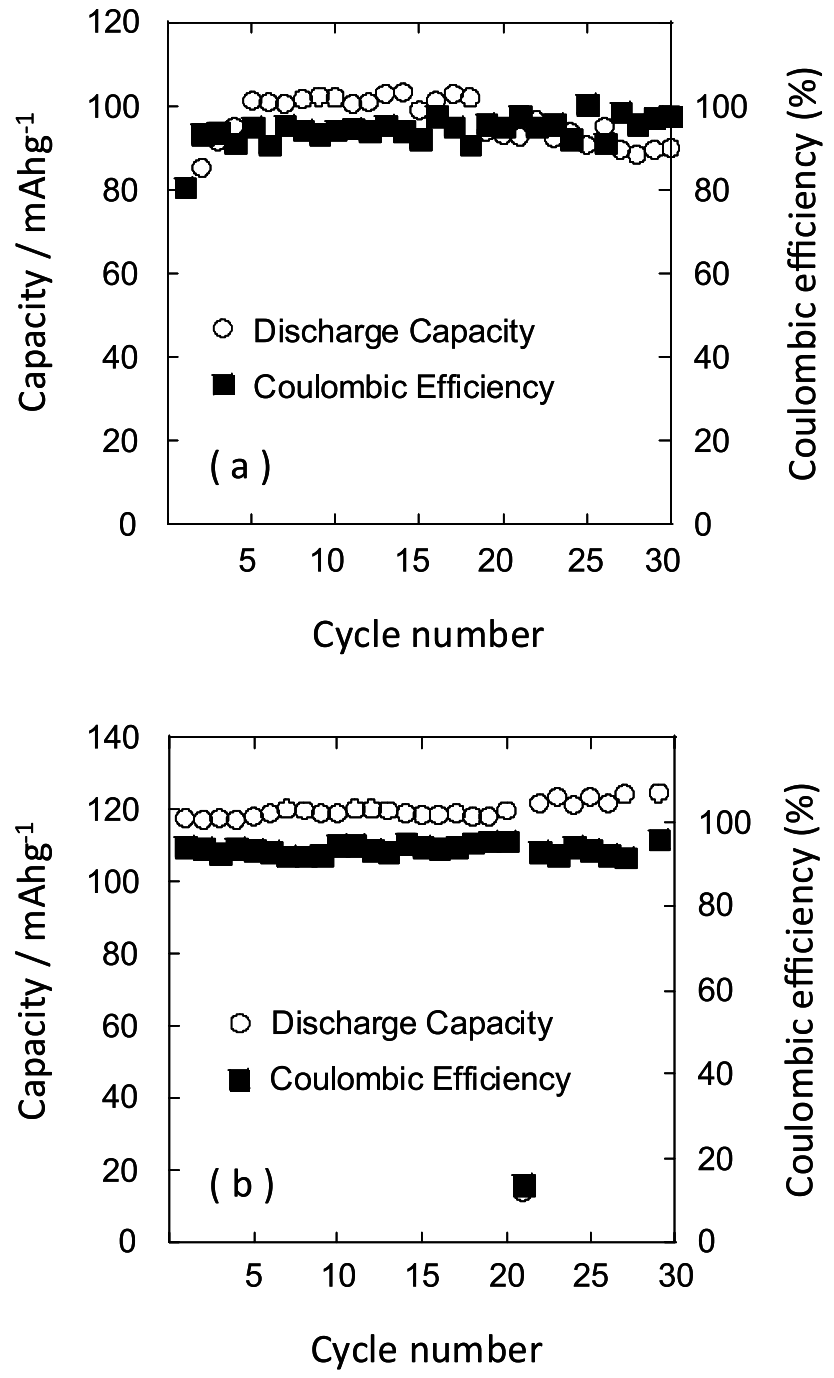

Fig. 2 Cycle behavior of discharge capacities and chargedischarge efficiencies of positive electrodes in the EMI$\mathrm{CmMI}$ ionic liquid electrolyte. Electrode: (a) $\mathrm{LiMn}_{2} \mathrm{O}_{4}$ (b) $\mathrm{LiFePO}_{4}$. Current density: $0.02 \mathrm{~mA} \mathrm{~cm}{ }^{-2}$, Cut-off voltage: (a) $3.5-4.6 \mathrm{~V}$, (b) $2.5-3.8 \mathrm{~V}$.

CmMI, and PP13 are ca. $160{ }^{\circ} \mathrm{C}, 300{ }^{\circ} \mathrm{C}$, and $250^{\circ} \mathrm{C}$, respectively. When EC : DEC electrolyte is coexisted with charged $\mathrm{LiMn}_{2} \mathrm{O}_{4}$ or $\mathrm{LiFePO}_{4}$, the self-heating is $c a .170{ }^{\circ} \mathrm{C}$ or $c a .120^{\circ} \mathrm{C}$, basically similar to the case of electrolyte itself. Both ionic liquid electrodes appear to contribute to improve the self-heating temperature up to around $250{ }^{\circ} \mathrm{C}$ regardless of the positive electrode. Under the coexistence of charged positive electrodes, the self-heating temperature in the EMI : CmMI electrolyte becomes slightly lower than that in the PP13, probably due to the reaction with electrodes around $250{ }^{\circ} \mathrm{C}$. The rate of temperature increase under adiabatic atmosphere is considered to suggest roughly the rate of the self-heating. The temperature increase rates in this region in the ionic liquid electrolytes appear to be suppressed compared with that in the EC : DEC electrolyte, while the difference of heat capacity among these electrolytes should be taken into consideration for more precise discussion. In addition, the experimental condition is to be investigated further because the results in Fig. 3 show rather minor
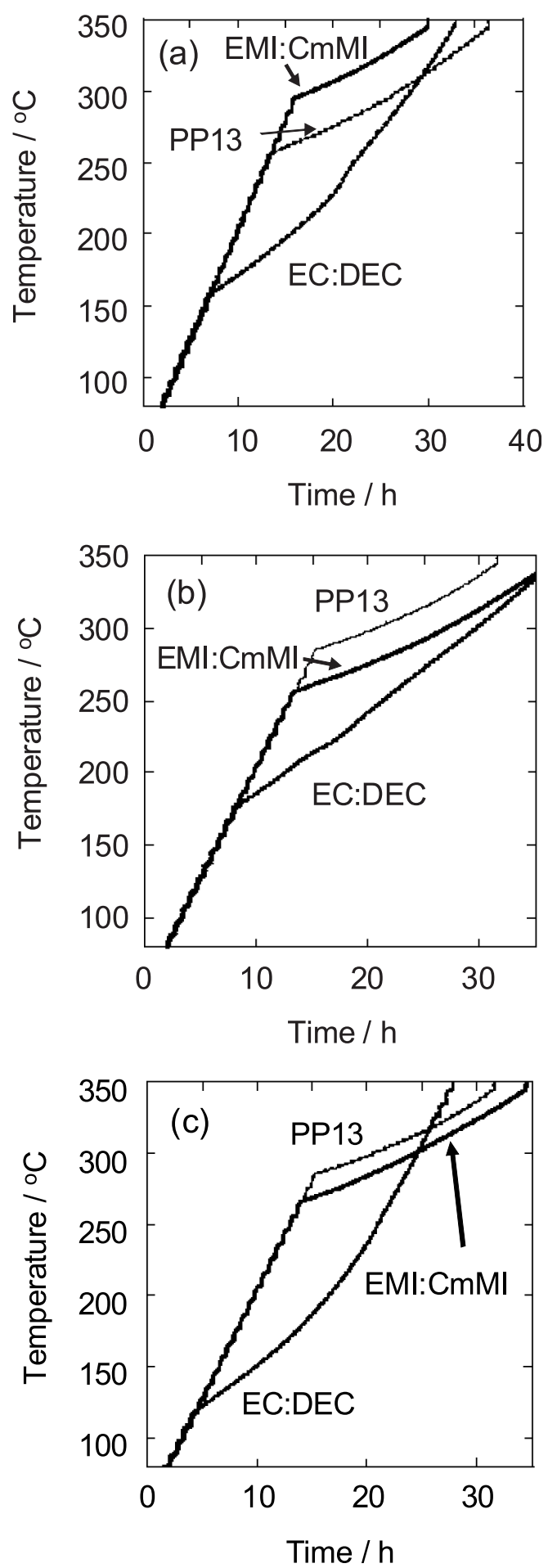

Fig. 3 ARC temperature profiles of various electrolytes with coexistence of charged positive electrode. Electrode: (a) none (b) $\mathrm{LiMn}_{2} \mathrm{O}_{4}$ (c) $\mathrm{LiFePO}_{4}$. Status of positive electrode: after constant-current charge to (b) $4.6 \mathrm{~V}$ and (c) $3.8 \mathrm{~V}$. Heating step: $10 \mathrm{~K} / 30 \mathrm{~min}$. Sample: $0.3 \mathrm{~cm}^{-3}$ electrolyte with ca. $0.01 \mathrm{~g}$ electrode.

influence of positive electrode than expected.

The compatibility of graphite and hard carbon electrodes in the EMI: CmMI electrolyte is to be estimated by the charge-discharge profiles of these electrodes shown in Fig. 4. KS-6 graphite electrode exhibits a large irreversible capacity at initial charging (lithium intercala- 

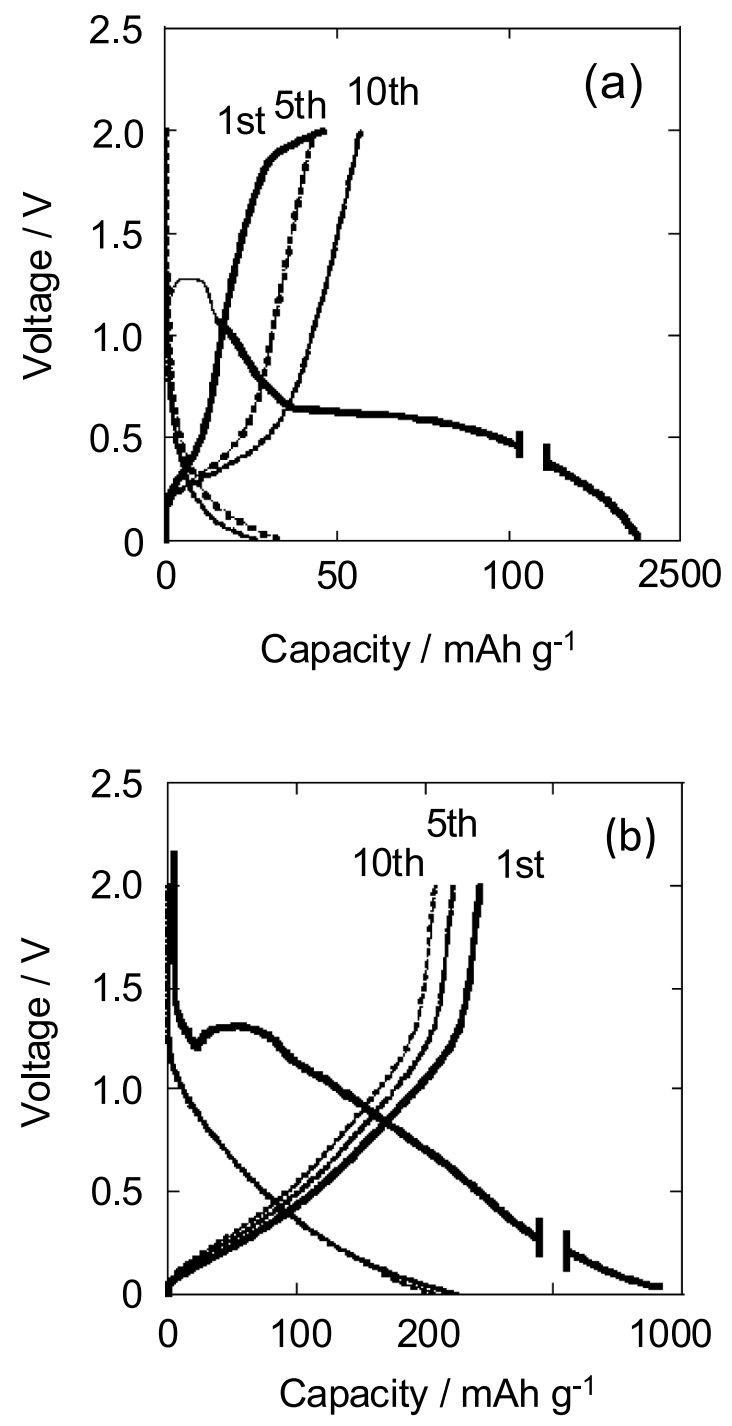

Fig. 4 Charge-discharge profiles of the $\mathrm{Li} /$ carbonaceous negative electrode cells in the EMI : CmMI ionic liquid electrolyte. Electrode: (a) KS-6 graphite (b) Carbotron P. Current density: $0.02 \mathrm{~mA} \mathrm{~cm}{ }^{-2}$, Cut-off voltage: $-0.01-2.0 \mathrm{~V}$.

tion) process and very small subsequent reversible capacities. In other words, the reversible lithium intercalation in the graphite electrode is inhibited by the initial reductive process, likely containing the formation of surface insulating layer by the decomposition product of the electrolyte and the decomposition of the graphite structure. In contrast, the hard carbon electrode exhibits significant reversible capacity as large as $200 \mathrm{mAh} \mathrm{g}^{-1}$, while the large amount of irreversible capacity is observed at initial charging process. The EMI : CmMI mixed electrolyte contains large amount of EMI, which decomposes at as a low potential as $1 \mathrm{~V}$ vs. $\mathrm{Li} / \mathrm{Li}^{+}$. Therefore the behavior of the graphite electrode sounds rather reasonable. Nevertheless, the hard carbon electrode exhibits stable charge-discharge in this electrolyte. Such stable charge-discharge is considered to be promoted by some surface protective film provided by CmMITFSI. The authors have clarified that the mixed ionic liquid electrolyte containing CmMITFSI can provide an effective surface protective film on lithium metal electrode under a certain condition. ${ }^{20,21)}$ In the case of the hard carbon electrode, the decomposition product of the electrolyte may act effectively as a protective film. In this stage the difference of the electrolyte decomposition product on a graphite electrode from the one on a hard carbon is still unclear. One possibility comprised from the similar results reported by $\mathrm{Ui}$ et al. ${ }^{23)}$ is that the lithium intercalation process into the graphite in this ionic liquid electrolyte is inhibited even with the coexistence of intrinsically effective protective film.

The above results clearly indicate the potential of the mixed ionic liquid electrolyte EMITFSI-CmMITFSILiTFSI for lithium ion batteries, while a number of points for improvement, such as high-rate capability (because the above performances of positive and negative electrodes were observed at current density as low as $1 / 10 C$ ), electrolyte penetration into porous electrode, and irreversible capacity of carbon electrode at initial charging, still remains. The thermal stability of charged positive electrodes with this electrolyte is an expecting aspect for the improvement of battery cell safety. Further modification of this kind of electrolyte, e.g., the optimization of composition, the application of additives, the selection and design of appropriate electrodes, may provide a useful candidate for advanced cell candidate.

\section{Acknowledgement}

The present study is financially supported by the New Energy and Industrial Technology Development Organization (NEDO).

\section{References}

1) V. R. Koch, C. Nanjundiah, G. B. Appetecchi, and B. Scrosati, J. Electrochem. Soc., 142, L116 (1995).

2) J. Sun, M. Forsyth, and D. R. MacFarlane, J. Phys. Chem., 102, 8858 (1998).

3) D. R. MacFarlane, P. Meakin, J. Sun, N. Amini, and M. Forsyth, J. Phys. Chem. B, 103, 4164 (1999).

4) H. Sakaebe and H. Matsumoto, Electrochem. Commun., 5, 594 (2003).

5) T. Sato, T. Maruo, S. Marukane, and K. Takagi, J. Power Sources, 138, 253 (2004).

6) M. Egashira, S. Okada, J. Yamaki, D. A. Dri, F. Bonadies, and B. Scrosati, J. Power Sources, 138, 240 (2004).

7) K. Hayashi, Y. Nemoto, K. Akuto, and Y. Sakurai, J. Power Sources, 146, 689 (2005).

8) M. Ishikawa, T. Sugimoto, M. Kikuta, E. Ishiko, and M. Kono, J. Power Sources, 162, 658 (2006).

9) A. Fernicola, F. Croce, B. Scrosati, T. Watanabe, and H. Ohno, J. Power Sources, 174, 342 (2007).

10) K. Tsunashima and M. Sugiya, Electrochem. Solid-State Lett., 11, A17 (2008).

11) N. Koura, K. Iizuka, Y. Idemoto, and K. Ui, Electrochemistry, 67, 706 (1999).

12) H. Nakagawa, S. Izuchi, K. Kuwana, T. Nukuda, and Y. Aihara, J. Electrochem. Soc., 150, A695 (2003).

13) B. Garcia, S. Lavallée, G. Perron, C. Michot, and M. Armand, Electrochim. Acta, 49, 4583 (2004).

14) E. Markevich, V. Baranchugov, and D. Aurbach, Electrochem. Commun., 8, 1331 (2006). 
15) H. Zheng, B. Li, Y. Fu, T. Abe, and Z. Ogumi, Electrochim. Acta, 52, 1556 (2006).

16) M. Egashira, M. Tanaka-Nakagawa, I. Watanabe, S. Okada, J. Yamaki, J. Power Sources, 160, 1387 (2006).

17) S. Seki, Y. Ohno, H. Miyashiro, Y. Kobayashi, A. Usami, Y. Mita, N. Terada, K. Hayamizu, S. Tsuzuki, and M. Watanabe, J. Electrochem. Soc., 155, A421 (2008).

18) A. Guefi, S. Duchesne, Y. Kobayashi, A. Vijh, and K. Zaghib, J. Power Sources, 175, 866 (2008).

19) Y. Wang, K. Zaghib, A. Guerfi, F. F. C. Bazito, R. M.
Torresi, and J. R. Dahn, Electrochim. Acta, 52, 6346 (2007).

20) M. Egashira, H. Todo, N. Yoshimoto, M. Morita, and J. Yamaki, J. Power Sources, 174, 560 (2007).

21) L. Zhao, J. Yamaki, and M. Egashira, J. Power Sources, 174, 352 (2007).

22) M. Egashira, M. Sumimoto, N. Yoshimoto, M. Morita, and K. Hori, Electrochemistry, 77, 237 (2009).

23) K. Ui, T. Minami, K. Ishikawa, Y. Idemoto, and N. Koura, J. Power Sources, 146, 698 (2005). 